\title{
Editorial: Process Data in Educational and Psychological Measurement
}

\author{
Hong Jiao $^{1 *}$, Qiwei He ${ }^{2 *}$ and Bernard P. Veldkamp ${ }^{3 *}$ \\ ${ }^{1}$ Department of Human Development and Quantitative Methodology, University of Maryland, College Park, MD, \\ United States, ${ }^{2}$ Educational Testing Service, Princeton, NJ, United States, ${ }^{3}$ Department of Learning, Data Analytics and \\ Technology, Faculty of Behavioral Management and Social Sciences, University of Twente, Enschede, Netherlands
}

Keywords: process data, psychological assessment, data mining, educational assessment, computer based assessment

\section{Editorial on the Research Topic}

\section{Process Data in Educational and Psychological Measurement}

The increasing use of computer-based testing and learning environments is leading to a significant reform on the traditional form of measurement, with tremendous extra available data collected during the process of learning and assessment (Bennett et al., 2007, 2010). It means that we can learn and describe the respondents' performances not only by their responses, but also their responding processes, in addition to the response accuracy in the traditional tests (Ercikan and Pellegrino, 2017).

Edited and reviewed by: Huali Wang,

Peking University Sixth Hospital, China

*Correspondence:

Hong Jiao

hiiao@umd.edu

Qiwei He

qhe@ets.org

Bernard P. Veldkamp b.p.veldkamp@utwente.nl

Specialty section:

This article was submitted to Quantitative Psychology and Measurement, a section of the journal

Frontiers in Psychology

Received: 12 October 2021 Accepted: 25 October 2021 Published: 03 December 2021

Citation: Jiao H, He Q and Veldkamp BP (2021) Editorial: Process Data in Educational and Psychological Measurement. Front. Psychol. 12:793399 doi: 10.3389/fpsyg.2021.793399
The recent advances in computer technology enhance the convenient collection of process data in computer-based assessment. One such example is time-stamped action data in an innovative item which allow for the interaction between a respondent and the item. When a respondent attempts an interactive item, his/her actions are recorded, in the form of an ordered sequence of multi-type, time-stamped events. These sorts of data stored in log files, referred to as process data in this book, provide information beyond response data that typically show response accuracy only. This additional information holds promise to help us understand the strategies that underlie test performance and identify key actions that lead to success or failure of answering an item (e.g., Han et al., 2019; Liao et al.; Stadler et al., 2019; He et al., 2021; Ulitzsch et al., 2021a; Xiao et al., 2021).

With the availability of process data in addition to response data, the measurement field is becoming increasingly interested in borrowing additional auxiliary information from the responding process to serve different assessment purposes. For instance, recently researchers proposed different models for response time and the joint modeling of responses and response time (e.g., Bolsinova and Molenaar; Costa et al.; Wang et al.). In addition, other process data such as the path collected based on eye-tracking devices (e.g., Zhu and Feng, 2015; Maddox et al., 2018; Man and Harring, 2021), action sequences in problem-solving tasks (e.g., Chen et al.; Tang et al., 2020; He et al., 2021; Ulitzsch et al., 2021b), and processes in collaborative problem solving (e.g., Graesser et al., 2018; Andrews-Todd and Kerr, 2019; De Boeck and Scalise, 2019), are also worthy of exploration and integration with product data for assessment purposes.

This Research Topic (formed in this edited e-book) intends to explore the forefront of responding to the needs in modeling new data sources and incorporating process data in the statistical modeling of multiple possible assessment data. This edited book presents the cuttingedge research related to utilizing process data in addition to product data such as item responses in educational and psychological measurement for enhancing accuracy in ability parameter 
estimation (e.g., Bolsinova and Molenaar; De Boeck and Jeon; Engelhardt and Goldhammer; Klotzke and Fox; Liu C. et al.; Park et al.; Schweizer et al.; Wang et al.; Zhang and Wang), cognitive diagnosis facilitation (e.g., Guo and Zheng; Guo et al.; Jiang and Ma; Zhan, Liao et al.; Zhan, Jiao et al.), and aberrant responding behavior detection (e.g., Liu H. et al.; Toton and Maynes).

Throughout the book, the methods for analyzing process data in technology-enhanced innovative items in large-scale assessment for high-stakes decisions are addressed (e.g., Lee et al.; Stadler et al.). Further, the methods for the extraction of useful information in process data in assessments such as serious games and simulations were also discussed (e.g., Liao et al.; Kroehne et al.; Ren et al.; Yuan et al.). The interdisciplinary studies that borrow data-driven methods from computer science, machine learning, artificial intelligence, and natural language processing are also highlighted in this Research Topic (e.g., Ariel-Attali et al.; Chen et al.; Hao and Mislevy; Qiao and Jiao; Smink et al.), which provide new perspectives in data exploration in educational and psychological measurement. Most importantly, the models presenting the integration of the process data and the product data in this book are of critical significance to link the traditional test data with the new features extracted from the new data sources. Meanwhile, the papers included in the book provide an excellent source for data and coding sharing, which entails significant contributions to the applications of the innovative statistical modeling of assessment data in the measurement field.

The book chapters demonstrate the use of process data and the integration of process and product data (item responses) in educational and psychological measurement. The chapters address issues in adaptive testing, problem-solving strategy, validity of test score interpretation, item pre-knowledge detection, cognitive diagnosis, complex dependence in joint modeling of responses and response time, and multidimensional modeling of these data types. The originality of this book lies in the statistical modeling of innovative assessment data such as log data, response time data, collaborative problemsolving tasks, dyad data, change process data, testlet data, and multidimensional data. Further, new statistical models are presented for analyzing process data in addition to response data such as transition profile analysis, the event history analysis approach, hidden Markov modeling, conditional scaling, multilevel modeling, text mining, Bayesian covariance structure modeling, mixture modeling, and multidimensional modeling. The integration of multiple data sources and the use of process data provides the measurement field with new perspectives to solve assessment issues and challenges such as problem-solving strategy, cheating detection, and cognitive diagnosis.

An overview of all the papers included in this Research Topic is summarized in Table 1 with respect to their key features. The scope of the Research Topic can be classified into five major categories:

(1) leveraging process data to explore test-takers' behaviors and problem-solving strategies,
(2) proposing joint modeling for response accuracy and response times,

(3) proposing new statistical models on analyzing response processes (e.g., time-stamped sequential events),

(4) advancing cognitive diagnostic models with new data sources, and

(5) using data streams in estimating collaborative problemsolving skills.

The above categorization focused on each paper's core contribution though some papers can be cross-classified. The papers' key findings and advancements impressively represent the current state-of-the-art methods in the field of process data analysis in educational and psychological assessments. As topic editors, we were happy to receive such a great collection of papers with various foci and submit these publications right as digital assessments are booming. The papers collected in this Research Topic are also diverse in data types, statistical approaches, and assessment with an extensive scope in both high-stake and low-stake assessments, covering research fields in education, psychology, health, and other applied disciplines.

As one of the first comprehensive books addressing the modeling and application of process data, this e-book has drawn great attention since its debut was cross-loaded on three journals in Frontiers in Psychology, Frontiers in Education, and Frontiers in Applied Mathematics and Statistics. With 29 papers from 77 authors, this book enhances interdisciplinary research in fields such as psychometrics, psychology, statistics, computer science, educational technology, and educational data mining, to name a few. As highlighted on the e-book webpage, (https://www.frontiersin.org/research-topics/7035/ process-data-in-educational-and-psychological-measurement\# impact) on November 13, 2021, this e-book has accumulated 115,069 total reviews and 17,940 article downloads since the Research Topic project launched in 2017. This number keeps growing on a daily basis. The diversified demographics provide convincing evidence that the papers in this book reached the global research community, addressing the critical issues of statistical modeling of multiple types of assessment data in the digital era. This book is just on time to provide tools and methods to shape this new measurement horizon.

As more and more data are being collected in computer-based testing, process data will become a very important source of information to validate and facilitate measuring response accuracy and provide supplementary information in understanding test-takers' behaviors, the reasons of missing data, and links with motivation studies. There is no doubt that there is high demand of such research in the large-scale assessment, both high-stake and low-stake, as well as in the personalized learning and assessment to tailor the best source and methods to help people learn and grow. This book is a timely addition to the current literature on psychological and educational measurement. It is expected to be applied 
TABLE 1 | An overview of papers collected in this Research Topic.

\begin{tabular}{|c|c|c|c|c|}
\hline References & Areas of advancement & Data types & Statistical approaches & Assessment domains \\
\hline \multicolumn{5}{|c|}{ Leveraging process data to explore test-takers' behaviors and strategies } \\
\hline Ren et al. & $\begin{array}{l}\text { Exploring multiple goals in interactive } \\
\text { problem-solving items }\end{array}$ & $\begin{array}{l}\text { Extracted response process } \\
\text { variables, correctness of } \\
\text { responses }\end{array}$ & $\begin{array}{l}\text { Cluster analysis, logistics, } \\
\text { and least-squares } \\
\text { regression }\end{array}$ & $\begin{array}{l}\text { Interactive problem-solving } \\
\text { in PISA } 2012\end{array}$ \\
\hline $\begin{array}{l}\text { Engelhardt and } \\
\text { Goldhammer }\end{array}$ & $\begin{array}{l}\text { Proposing a validity research that } \\
\text { uses processing times to provide } \\
\text { both convergent and discriminant } \\
\text { validity evidence for the construct } \\
\text { interpretation of reasoning and } \\
\text { reading ability scores }\end{array}$ & Response data, response times & $\begin{array}{l}\text { MLR estimator (maximum } \\
\text { likelihood estimation with } \\
\text { robust standard error) }\end{array}$ & $\begin{array}{l}\text { PIAAC } 2012 \text { literacy } \\
\text { assessments }\end{array}$ \\
\hline Stadler et al. & $\begin{array}{l}\text { Exploring successful and } \\
\text { unsuccessful strategies with process } \\
\text { data in complex problem-solving } \\
\text { items }\end{array}$ & $\begin{array}{l}\text { Response process data, } \\
\text { correctness of responses }\end{array}$ & N-grams model & $\begin{array}{l}\text { Interactive problem-solving } \\
\text { items }\end{array}$ \\
\hline Lee et al. & $\begin{array}{l}\text { Exploring response times in complex } \\
\text { simulation-based tasks to understand } \\
\text { test-takers' interactions }\end{array}$ & Response data, response times & $\begin{array}{l}\text { Cluster analysis and } \\
\text { hierarchical framework for } \\
\text { joint modeling item } \\
\text { responses and response } \\
\text { times }\end{array}$ & $\begin{array}{l}\text { Interactive problem-solving } \\
\text { items }\end{array}$ \\
\hline Toton and Maynes & $\begin{array}{l}\text { Detecting examinees with } \\
\text { pre-knowledge in experimental data } \\
\text { with conditional scaling of response } \\
\text { times }\end{array}$ & Item scores, response times & $\begin{array}{l}\text { Cluster analysis, factor } \\
\text { analysis }\end{array}$ & $\begin{array}{l}\text { Simulation study and } \\
\text { empirical study in GRE } \\
\text { quantitative testing }\end{array}$ \\
\hline Arieli-Attali et al. & $\begin{array}{l}\text { Understanding test-takers' choices } \\
\text { using hidden Markov modeling of } \\
\text { process data }\end{array}$ & $\begin{array}{l}\text { Response data, answer change, } \\
\text { item difficulty }\end{array}$ & Hidden Markov model & Self-adapted tests \\
\hline Qiao and Jiao & $\begin{array}{l}\text { Using data mining techniques in } \\
\text { analyzing process data and making } \\
\text { comparisons among } \\
\text { machine-learning algorithms in } \\
\text { exploring problem-solving items }\end{array}$ & $\begin{array}{l}\text { Extracted response process } \\
\text { variables, correctness of } \\
\text { responses }\end{array}$ & $\begin{array}{l}\text { Multiple machine learning } \\
\text { algorithms: supervised } \\
\text { techniques (CART, gradient } \\
\text { boosting, random forest, } \\
\text { and SVM), unsupervised } \\
\text { techniques (SOM, k-means) }\end{array}$ & $\begin{array}{l}\text { Interactive problem-solving } \\
\text { in PISA } 2012\end{array}$ \\
\hline Liu H. et al. & $\begin{array}{l}\text { Exploring test-takers' problem-solving } \\
\text { strategies with a modified multilevel } \\
\text { mixture IRT model }\end{array}$ & $\begin{array}{l}\text { Extracted response process } \\
\text { variables, correctness of } \\
\text { responses }\end{array}$ & $\begin{array}{l}\text { Modified multilevel mixture } \\
\text { IRT model, latent class } \\
\text { analysis }\end{array}$ & $\begin{array}{l}\text { Interactive problem-solving } \\
\text { in PISA } 2012\end{array}$ \\
\hline Liao et al. & $\begin{array}{l}\text { Exploring sequential patterns in } \\
\text { problem-solving items and } \\
\text { relationship with individual differences }\end{array}$ & $\begin{array}{l}\text { Extracted response process } \\
\text { variables, response data, } \\
\text { background variables }\end{array}$ & $\begin{array}{l}\mathrm{N} \text {-grams model, feature } \\
\text { selection model, regression } \\
\text { analysis }\end{array}$ & $\begin{array}{l}\text { PIAAC } 2012 \\
\text { problem-solving in } \\
\text { technology-rich environmen }\end{array}$ \\
\hline
\end{tabular}

Joint model for response accuracy and response times

Zhan, Jiao et al.

Costa et al.

Guo et al.

Klotzke and Fox

Kroehne et al.
Proposing a joint model fo multidimensional abilities and multifactor speed

Proposing a joint model for item response and time-on-task to increase the precision of ability estimates

Proposing a joint model for a speed-accuracy tradeoff hierarchical model based on cognitive experiment

Proposing a Bayesian modeling framework for response accuracy, response times, and other process data variables

Proposing a parameterized joint model of response data and response time to detect invariance by gender and mode between computer-based and paper-based tests
Extracted response process responses

Response data, response times

MLR estimator (maximum kelihood estimation with joint modeling item times

analysis, factor analysis

Response data, response times

Response data, response times

Response data, response times

Response data, response times, extracted response process variables

Response data, response times
Joint modeling of response and response time, exploratory factor analysis

Multidimensional latent model for response and response time

Bayesian MCMC algorithm, speed-accuracy hierarchical model

Bayesian covariance structure models

Bivariate generalized linear IRT model framework (B-GLIRT)
Simulation study and empirical study in computer-based math assessment (PISA 2012) Interactive problem-solving in PISA 2012

Simulation study and empirical study in Raven's Standard Progressive Matrices

Simulation study and empirical study in PIAAC 2012 cognitive assessments

PISA 2012 and PISA 2009 reading assessments 
TABLE 1 | Continued

\begin{tabular}{ll}
\hline References & Areas of advancement \\
\hline De Boeck and Jeon & $\begin{array}{l}\text { An overview of models for joint } \\
\text { modeling of response times and } \\
\text { response accuracy in cognitive tests }\end{array}$ \\
Wang et al. & $\begin{array}{l}\text { Modeling response time and } \\
\text { responses in multidimensional health } \\
\text { measurement }\end{array}$ \\
Zhang and Wang & $\begin{array}{l}\text { Proposing a mixture learning model } \\
\text { that utilizes the response times and } \\
\text { response accuracy in learning } \\
\text { progression } \\
\text { Proposing a joint model for response } \\
\text { accuracy and response times with } \\
\text { consideration on non-linear } \\
\text { conditional dependence }\end{array}$ \\
\hline Molsinova and
\end{tabular}

\section{Statistical model on response process}

Smink et al.

Therapeutic change process research through multilevel and text mining

Schweizer et al

Investigating how the major outcome of a confirmatory factor investigation is preserved when scaling the variance of a latent variable by the various scaling methods

\section{Liu C. et al.}

Park et al

Chen et al.

\section{Proposing a model with a leakage} parameter to better characterize the item leaking process and develop a more generalized detection method by monitoring responses of test-takers

Proposing a multidimensional IRT approach for dynamically monitoring ability growth in adaptive learning systems Proposing an event history analysis approach to predict duration and outcome of solving a complex problem by making use of process data

\section{Data types}

Response data, response times

Response data, response times

Response data, response times

Response data, response times

Life narratives textual data and response data

Scaling data

Response data

Response data, response times

Time-stamped sequential events data, correctness of responses
Statistical approaches

Multiple response models

and joint models of

response data and

response times

Multidimensional-graded response model, hierarchical joint model of responses and response times

Diagnostic classification model framework, Bayesian estimation

Joint model for quadratic conditional dependence, joint model for multiple-category conditional dependence, indicator-level non-parametric moderation method

Multilevel models, text mining

Multiple confirmatory factor analysis

Generalized linear model for detection, leakage simulation model

Multidimensional IRT

Regression model

Multiple cognitive diagnostic models

Log-linear cognitive diagnostic model with EM algorithm, differential evolution

Response data, response times
Response data, test

Response data differential evolution optimization into the EM framework in the log-linear cognitive diagnostic model estimation

Zhan, Liao et al.
Proposing a joint testlet cognitive diagnostic model for paired local item dependence using response time and response accuracy
Joint testlet cognitive diagnosis modeling
Assessment domains

Literature review

Health measurement

Simulation study and empirical study in a computer-based learning environment

Simulation study and empirical study in high-stakes arithmetic assessment

Epidemiologic Studies Depression Scale and life narratives (CES-D)

Simulation study and empirical study in Multitrait-Multimethod (MTMM) design

Simulation study and empirical study in operational computerized adaptative testing

Simulation study and web-based learning platform

Interactive problem-solving in PISA 2012

Simulation study

Simulation study and empirical study in assessment of a health profession

PISA 2015 computer-based math assessment 
TABLE 1 | Continued

\begin{tabular}{|c|c|c|c|c|}
\hline References & Areas of advancement & Data types & Statistical approaches & Assessment domains \\
\hline \multicolumn{5}{|c|}{ Using data streams for estimating collaborative problem-solving skills } \\
\hline Hao and Mislevy & $\begin{array}{l}\text { Characterizing interactive } \\
\text { communications in collaborative } \\
\text { problem-solving using a conditional } \\
\text { transition profile approach }\end{array}$ & $\begin{array}{l}\text { Conversations collected in a } \\
\text { computer-based collaborative } \\
\text { problem-solving platform }\end{array}$ & $\begin{array}{l}\text { Conditional transition profile, } \\
\text { cluster analysis }\end{array}$ & $\begin{array}{l}\text { Collaborative } \\
\text { problem-solving platform }\end{array}$ \\
\hline Yuan et al. & $\begin{array}{l}\text { Assessing collaborative } \\
\text { problem-solving competence by } \\
\text { extracting indictors from process } \\
\text { stream data and modeling dyad data }\end{array}$ & $\begin{array}{l}\text { Process stream data in } \\
\text { collaborative problem solving, } \\
\text { response data }\end{array}$ & $\begin{array}{l}\text { Multidimensional Random } \\
\text { Coefficients Multinomial } \\
\text { Logit Model (MRCMLM) }\end{array}$ & $\begin{array}{l}\text { Collaborative } \\
\text { problem-solving platform } \\
\text { adapted from a } \\
\text { problem-solving task in } \\
\text { PISA } 2012\end{array}$ \\
\hline
\end{tabular}

more extensively in educational and psychological measurement, such as in computerized adaptive testing and dynamic learning.

\section{AUTHOR CONTRIBUTIONS}

All authors listed have made a substantial, direct, and intellectual contribution to the work and approved it for publication.

\section{REFERENCES}

Andrews-Todd, J., and Kerr, D. (2019). Application of ontologies for assessing collaborative problem-solving skills. Int. J. Testing 19, 172-187. doi: 10.1080/15305058.2019.1573823

Bennett, R. E., Persky, H., Weiss, A., and Jenkins, F. (2010). Measuring problem solving with technology: A demonstration study for NAEP. J. Technol. Learn. Assessment 8, 1-44. Retrieved from https://ejournals.bc.edu/index.php/jtla/ article/view/1627

Bennett, R. E., Persky, H., Weiss, A. R., and Jenkins, F. (2007). Problem Solving in Technology-Rich Environments. A Report From the NAEP Technology Based Assessment Project, Research and Development Series (NCES 2007-466). National Center for Education Statistics.

De Boeck, P., and Scalise, K. (2019). Collaborative problem solving: Processing actions, time, and performance. Front. Psychol. 10:1280. doi: 10.3389/fpsyg.2019.01280

Ercikan, K., and Pellegrino, J. W. (Eds.). (2017). Validation of Score Meaning for the Next Generation of Assessments: The Use of Response Processes. New York, NY: Routledge.

Graesser, A. C., Fiore, S. M., Greiff, S., Andrews-Todd, J., Foltz, P. W., and Hesse, F. W. (2018). Advancing the science of collaborative problem solving. Psychol. Sci. Public Interest 19, 59-92. doi: 10.1177/1529100618808244

Han, Z., He, Q., and von Davier, M. (2019). Predictive feature generation and selection using process data from PISA interactive problemsolving items: an application of random forests. Front. Psychol. 10:2461. doi: $10.3389 /$ fpsyg. 2019.02461

He, Q., Borgonovi, F., and Paccagnella, M. (2021). Leveraging process data to assess adults' problem-solving skills: Identifying generalized behavioral patterns with sequence mining. Comp. Educ. 166:104170. doi: 10.1016/j.compedu.2021.104170

Maddox, B., Bayliss, A. P., Fleming, P., Engelhardt, P. E., Edwards, S. G., and Borgonovi, F. (2018). Observing response processes with eye tracking in international large-scale assessments: evidence from the OECD PIAAC assessment. Eur. J. Psychol. Educ. 33, 543-558. doi: 10.1007/s10212-018-0380-2

Man, K., and Harring, J. R. (2021). Assessing preknowledge cheating via innovative measures: A multiple-group analysis of jointly modeling item responses, response times, and visual fixation counts. Educ. Psychol. Meas. 81, 441-465. doi: $10.1177 / 0013164420968630$

\section{FUNDING}

QH was partially supported by the National Science Foundation grants IIS-1633353.

\section{ACKNOWLEDGMENTS}

We thank all authors who have contributed to this Research Topic and the reviewers for their valuable feedback on the manuscript.

Stadler, M., Fischer, F., and Greiff, S. (2019). Taking a closer look: an exploratory analysis of successful and unsuccessful strategy use in complex problems. Front. Psychol. 10:777. doi: 10.3389/fpsyg.2019.00777

Tang, X., Wang, Z., He, Q., Liu, J., and Ying, Z. (2020). Latent feature extraction for process data via multidimensional scaling. Psychometrika 85, 378-397. doi: 10.1007/s11336-020-09708-3

Ulitzsch, E., He, Q., and Pohl, S. (2021a). Using sequence mining techniques for understanding incorrect behavioral patterns on interactive tasks. J. Educ. Behav. Statistics 45, 59-96. doi: 10.3102/10769986211010467

Ulitzsch, E., He, Q., Ulitzsch, V., Nichterlein, A., Molter, H., Niedermeier, R., et al. (2021b). Combining clickstream analyses and graph-modeled data clustering for identifying common response process using time-stamped action sequence. Psychometrika 86, 190-214. doi: 10.1007/s11336-020-09743-0

Xiao, Y., He, Q., Veldkamp, B., and Liu, H. (2021). Exploring latent states of problem-solving competence using hidden markov modeling on process data. J. Comp. Assisted Learn. 37, 1232-1247. doi: 10.1111/jcal.12559

Zhu, M., and Feng, G. (2015). "An exploratory study using social network analysis to model eye movements in mathematics problem solving," in LAK '15: Proceedings of the Fifth International Conference on Learning Analytics and Knowledge, 383-387. doi: 10.1145/2723576.27 23591

Conflict of Interest: The authors declare that the research was conducted in the absence of any commercial or financial relationships that could be construed as a potential conflict of interest.

Publisher's Note: All claims expressed in this article are solely those of the authors and do not necessarily represent those of their affiliated organizations, or those of the publisher, the editors and the reviewers. Any product that may be evaluated in this article, or claim that may be made by its manufacturer, is not guaranteed or endorsed by the publisher.

Copyright (c) 2021 Jiao, He and Veldkamp. This is an open-access article distributed under the terms of the Creative Commons Attribution License (CC BY). The use, distribution or reproduction in other forums is permitted, provided the original author(s) and the copyright owner(s) are credited and that the original publication in this journal is cited, in accordance with accepted academic practice. No use, distribution or reproduction is permitted which does not comply with these terms. 